\title{
Determination of respiratory system compliance during pressure support ventilation by small variations of pressure support
}

\author{
Tobias Becher ${ }^{1}(\mathbb{1}) \cdot$ Dirk Schädler $^{1}\left(\mathbb{D} \cdot\right.$ Philipp Rostalski $^{2} \cdot$ Günther Zick $^{1}$ • \\ Inéz Frerichs $^{1} \cdot$ Norbert Weiler $^{1}$
}

Received: 5 April 2017 / Accepted: 16 September 2017 / Published online: 22 September 2017

(c) Springer Science+Business Media B.V. 2017

\begin{abstract}
In mechanically ventilated patients, measurement of respiratory system compliance $\left(\mathrm{C}_{\mathrm{rs}}\right)$ is of high clinical interest. Spontaneous breathing activity during pressure support ventilation (PSV) can impede the correct assessment of $\mathrm{C}_{\mathrm{rs}}$ and also alter the true $\mathrm{C}_{\mathrm{rs}}$ by inducing lung recruitment. We describe a method for determination of $\mathrm{C}_{\mathrm{rs}}$ during PSV and assess its accuracy in a study on 20 mechanically ventilated patients. To assess $\mathrm{C}_{\mathrm{rs}}$ during pressure support ventilation $\left(\mathrm{C}_{\mathrm{rs}, \mathrm{PSV}}\right)$, we performed repeated changes in pressure support level by $\pm 2 \mathrm{cmH}_{2} \mathrm{O}$. $\mathrm{C}_{\mathrm{rs}, \mathrm{PSV}}$ was calculated from the volume change induced by these changes in pressure support level, taking into account the inspiration time and the expiratory time constant. As reference methods, we used $\mathrm{C}_{\mathrm{rr}}$, measured during volume controlled ventilation $\left(\mathrm{C}_{\mathrm{rs}, \mathrm{VCV}}\right)$. In a post-hoc analysis, we assessed $\mathrm{C}_{\mathrm{rs}}$ during the last $20 \%$ of the volume-controlled inflation $\left(\mathrm{C}_{\mathrm{rs}, \mathrm{VCV} 20}\right)$. Values were compared by linear regression and Bland-Altman methods comparison. Comparing $\mathrm{C}_{\mathrm{rs}, \mathrm{PSV}}$ to the reference value $\mathrm{C}_{\mathrm{rs}, \mathrm{VCV}}$, we found a coefficient of determination $\left(\mathrm{r}^{2}\right)$ of 0.90 , but a relatively high bias of $-7 \mathrm{ml} / \mathrm{cm} \mathrm{H}_{2} \mathrm{O}(95 \%$ limits of agreement -16.7 to $+2.7 \mathrm{ml} / \mathrm{cmH}_{2} \mathrm{O}$ ). Comparison with $\mathrm{C}_{\mathrm{rs}, \mathrm{VCV} 20}$ resulted in a negligible bias $\left(-1.3 \mathrm{ml} / \mathrm{cmH}_{2} \mathrm{O}\right.$, $95 \%$ limits of agreement -13.9 to +11.3$)$ and $r^{2}$ of 0.81 . We conclude that the novel method provides an estimate of
\end{abstract}

Tobias Becher and Dirk Schädler have contributed equally to this work.

Dirk Schädler

dirk.schaedler@uksh.de

1 Department of Anesthesiology and Intensive Care Medicine, University Medical Center Schleswig-Holstein, Campus Kiel, Arnold-Heller-Straße 3, Haus 12, 24105 Kiel, Germany

2 Institute for Electrical Engineering and Medicine, Universität zu Lübeck, Moislinger Allee 53-55, 23558 Lübeck, Germany end-inspiratory $\mathrm{C}_{\mathrm{rs}}$ during PSV. Despite its limited accuracy, it might be useful for non-invasive monitoring of $\mathrm{C}_{\mathrm{rs}}$ in patients undergoing pressure support ventilation.

Keywords Assisted mechanical ventilation · Pressure support · Pressure support ventilation · Respiratory system mechanics $\cdot$ Compliance $\cdot$ Oesophageal pressure measurement . Weaning from mechanical ventilation . Acute respiratory distress syndrome

\section{Introduction}

A valid measurement of respiratory system compliance $\left(\mathrm{C}_{\mathrm{rs}}\right)$ is essential in the assessment of the diseased lung status during mechanical ventilation [1-3] During volume-controlled ventilation $(\mathrm{VCV}), \mathrm{C}_{\mathrm{rs}}$ can be determined as tidal volume $\left(\mathrm{V}_{\mathrm{T}}\right)$ divided by the difference between plateau airway pressure $\left(\mathrm{P}_{\text {plat }}\right)$ and positive end-expiratory pressure (PEEP):

$C_{\mathrm{rs}}=\frac{V_{T}}{P_{\text {plat }}-\text { PEEP }}$

Alternatively, $\mathrm{C}_{\mathrm{rs}}$ and resistance $\left(\mathrm{R}_{\mathrm{rs}}\right)$ can be calculated during different modes of mechanical ventilation with a least squares fit (LSF) using the equation of motion of the respiratory system,

$\mathrm{P}_{\mathrm{aw}}(\mathrm{t})=\frac{V_{T}(\mathrm{t})}{C_{\mathrm{rs}}}+\mathrm{V}^{\prime}(\mathrm{t}) * \mathrm{R}_{\mathrm{rs}}+\mathrm{P}_{\mathrm{o}}$

where $\mathrm{P}_{\mathrm{aw}}$ denotes the measured airway pressure, $\mathrm{V}^{\prime}$ denotes air flow and $\mathrm{P}_{0}$ the mathematically estimated alveolar pressure at the beginning of inspiration. The LSF technique can also be used for assessment of intratidal changes in $\mathrm{C}_{\mathrm{rs}}$ during a volume-controlled inspiration [4]. A decrease in 
$\mathrm{C}_{\mathrm{rs}}$ during the course of inspiration can be interpreted as alveolar overdistension, whereas an increase in $\mathrm{C}_{\mathrm{rs}}$ during inspiration can be interpreted as an indicator of tidal recruitment $[4,5]$. Adjustment of mechanical ventilation according to the intratidal course of $\mathrm{C}_{\mathrm{rs}}$ has shown promising results in preliminary clinical studies $[6,7]$.

In clinical practice, a large number of patients are switched from controlled to assisted modes of mechanical ventilation like pressure support ventilation (PSV) early in the course of their disease [8]. In the presence of spontaneous breathing efforts, the results of the abovementioned equations become inaccurate due to the additional respiratory muscle pressure $\left(\mathrm{P}_{\text {mus }}\right)$ generated by the patient [9]. Different methods to overcome this problem have been proposed which employ some form of end-inspiratory airway occlusion for assessment of $\mathrm{C}_{\mathrm{rs}}$ when spontaneous breathing is present $[10,11]$. These methods require the patient to relax the respiratory muscles during the airway occlusion, a precondition that is not always met by patients undergoing assisted mechanical ventilation. Moreover, an endinspiratory occlusion interferes with the normal spontaneous breathing pattern during assisted modes of mechanical ventilation like PSV. Another method was recently proposed by Al-Rawas and coworkers, which elegantly transforms the equation of motion by applying the expiratory time constant to estimate $\mathrm{C}_{\mathrm{rs}}, \mathrm{R}_{\mathrm{rs}}$ and $\mathrm{P}_{\text {plat }}$ during various ventilatory modes [12]. This method may only be applied under the prerequisite that a time point during the course of inspiration is found, where the patient's $\mathrm{P}_{\text {mus }}$ is negligible $[13,14]$. This may not always be possible in patients with strong inspiratory efforts. Therefore, an alternative method for continuous monitoring of $\mathrm{C}_{\mathrm{rs}}$ during PSV is desirable.

It has been shown that the patient's adaptation to respiratory muscle loading and unloading does not occur immediately but with a latency of a few breaths [15]. If repeated small changes in pressure support during ongoing PSV have no immediate effect on $\mathrm{P}_{\text {mus }}$, it should be possible to calculate $\mathrm{C}_{\mathrm{rs}}$ from the change in $\mathrm{V}_{\mathrm{T}}$ induced by the change in PS, using the expiratory time constant to correct for different inspiration times and for the absence of an end-inspiratory pause. We hypothesized that this method could be used to obtain an accurate estimate of $\mathrm{C}_{\mathrm{rs}}$ during ongoing PSV.

\section{Materials and methods}

\subsection{Study setting}

The present study was a prospective, single-center pilot study involving 20 mechanically ventilated patients in two surgical intensive care units (ICUs). We included ICU patients who were on assisted mechanical ventilation with PSV or suitable for PSV as per clinical decision. Exclusion criteria were age $<18$ years, pregnancy, hemodynamic instability, and severe chronic obstructive pulmonary disease. The study was approved by the local ethics committee (A125/12, 23-05-2012) and written informed consent was obtained from the patients or their legal representatives before study inclusion.

\subsection{Preparation for the study}

All patients were ventilated with an Evita XL ventilator (Dräger Medical, Lübeck, Germany). PEEP setting was maintained at the level set by the physician in charge. $\mathrm{P}_{\mathrm{aw}}$ and $\mathrm{V}$ ' were recorded at the Y-piece of the breathing circuit using a Bicore 2 device (CareFusion, Yorba Linda, CA, USA) at a sampling rate of $100 \mathrm{~Hz}$. The study period consisted of two measurement periods that were applied to each patient in random order. Measurements were performed during VCV (measuring period VCV) and during PSV (measuring period PSV).

\subsection{Measuring period PSV}

Sedation was titrated to achieve a level on the Richmond Agitation and Sedation Scale (RASS) [16] of -2 to -3 . Pressure rise time ( $\mathrm{T}_{\text {ramp }}$ ) was set to $0.2 \mathrm{~s}$ and the pressure support termination criterion to $25 \%$ of peak inspiratory flow. The pressure support level was adapted to achieve a target $\mathrm{V}_{\mathrm{T}}$ of $6-8 \mathrm{ml} / \mathrm{kg}$ predicted body weight. The $100 \mathrm{~ms}$ occlusion pressure (P0.1) was measured as an indicator of respiratory drive.

For our experimental method, the pressure support level was manually increased or decreased for one single breath by $2 \mathrm{cmH}_{2} \mathrm{O}$ after every 5 th to 7 th breath. It was immediately switched back to the previous value for the next breath (Fig. 1). This was repeated 10 to 15 times. Subsequently, pressure support level was manually decreased by $2 \mathrm{cmH}_{2} \mathrm{O}$ after every 5 th -7 th breath and immediately returned to baseline for the next breath. This was also repeated 10-15 times.

\subsection{Measuring period VCV}

During measuring period VCV, the patients were sedated to obtain a value on the Richmond Agitation and Sedation Scale of -4 to -5 . The absence of spontaneous breathing activity was confirmed clinically and by visual analysis of the $\mathrm{P}_{\mathrm{aw}}$ and $\mathrm{V}$ ' curves. If spontaneous breathing activity was detected despite deep sedation, a non-depolarizing neuromuscular blocking agent was administered (Rocuronium, MSD Sharp \& Dohme GmbH, Haar, Germany) at a dose of $0.6 \mathrm{mg}$ per $\mathrm{kg}$ of predicted body weight. $\mathrm{V}_{\mathrm{T}}$ was adjusted to $6-8 \mathrm{ml} / \mathrm{kg}$ predicted body weight and respiratory rate was set to achieve clinically acceptable minute ventilation while avoiding air-trapping caused by 

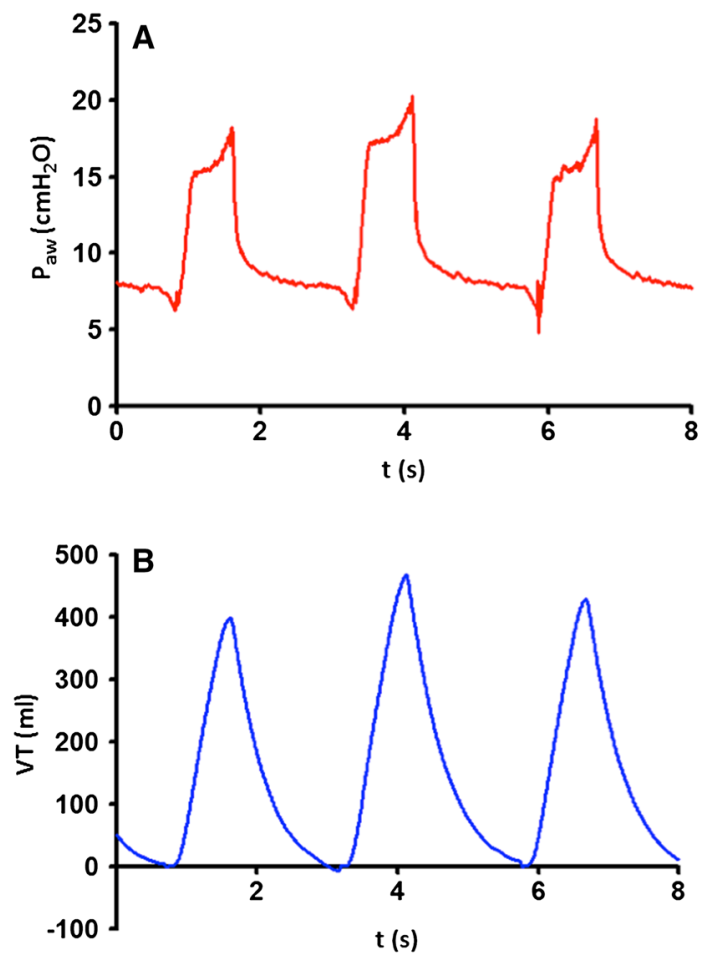

Fig. 1 An example of a patient examination with an increase in pressure support level by $2 \mathrm{cmH}_{2} \mathrm{O}$ during the second breath (a). The corresponding volume curve is displayed in $\mathbf{b}$. The increase in pressure support level lead to an increase in tidal volume of $69 \mathrm{ml} . P_{a w}$ airway pressure, $t$ time, $V_{T}$ tidal volume

incomplete expiration. $\mathrm{C}_{\mathrm{rs}}$ during $\mathrm{VCV}\left(\mathrm{C}_{\mathrm{rs}, \mathrm{VCV}}\right)$ was then determined during $\mathrm{VCV}$ with constant inspiratory flow and an end-inspiratory pause of at least $0.25 \mathrm{~s}$. These ventilator settings were also maintained for at least five consecutive breaths.

\subsection{Calculation of time constant during PSV}

For the calculation of the expiratory time constant $(\tau)$ during PSV, all expirations were divided into ten slices of equal volume (please see Fig. 2 for a schematic graphical illustration). The time constant $\tau$ was calculated separately for all volume slices as the slope of the flow-volume curve of each slice. Equally, the coefficient of determination $\left(\mathrm{r}^{2}\right)$ of the flow-volume curve was determined for each slice by using a linear regression fit. To determine $\tau_{\mathrm{PSV}}$ for an individual patient, the mean $\tau$ was calculated from all expiratory slices with an $r^{2}$ of $>0.95$ from ten consecutive breaths. To avoid disturbances from residual muscle activity or other interferences, the first and the last slice of every expiration and all slices with $\mathrm{r}^{2}<0.95$ were excluded from the analysis.

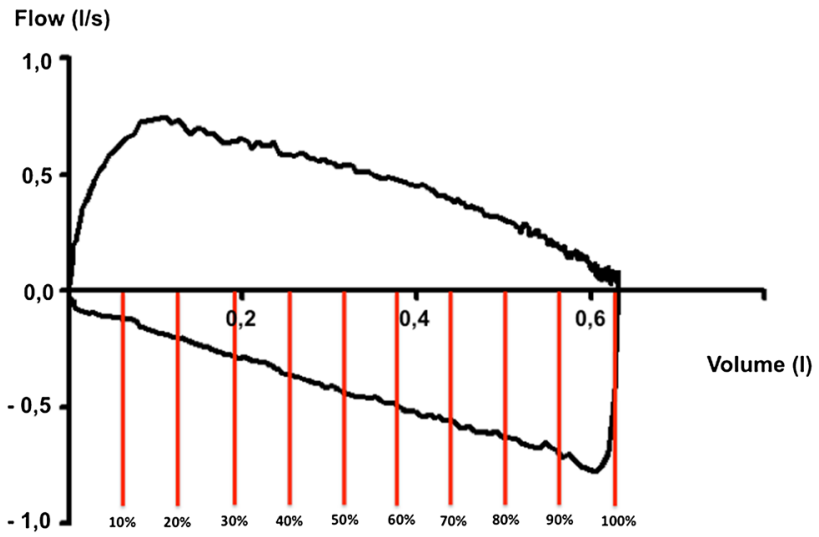

Fig. 2 Schematic representation of the division of the expiratory flow-volume loop into ten slices of equal volume. The expiratory time constant was determined as the mean slope of the regression lines from all slices with an almost linear flow-volume relationship, defined by a coefficient of determination $\left(\mathrm{r}^{2}\right)$ of more than 0.95 . The first and the last slice of every breath were ignored

\subsection{Calculation of compliance during PSV}

The compliance $\mathrm{C}_{\mathrm{rs}}$ during PSV $\left(\mathrm{C}_{\mathrm{rs}, \mathrm{PSV}}\right)$ was calculated from the change in tidal volume $\Delta \mathrm{V}_{\mathrm{T}}$ divided by the change in mean inspiratory $\mathrm{P}_{\mathrm{aw}}$ caused by the variation of pressure support $\left(\Delta \mathrm{P}_{\text {insp }}\right)$, considering $\mathrm{T}_{\text {ramp }}$, inspiration time $\left(\mathrm{T}_{\text {insp }}\right)$ and $\tau$. The solution of the linear equation of motion (Eq. 2) following an initial pressure ramp can be computed in closed form for $0 \leq \mathrm{t} \leq \mathrm{T}_{\text {Ramp }}$ :

$\mathrm{V}(\mathrm{t})=\mathrm{y}_{\text {ramp }}(\mathrm{t})=\mathrm{P}_{\text {insp }} \cdot \mathrm{C}_{\mathrm{rs}} \cdot\left(\mathrm{t}-\tau+\tau \cdot \mathrm{e}^{-\frac{\mathrm{t}}{\tau}}\right)$

The solution after changing to constant pressure at $\mathrm{t}_{1}=\mathrm{T}_{\text {ramp }}$ can be computed by superposition. A ramp with positive slope starting at $\mathrm{t}_{0}=0$ and continuing until $\mathrm{t}_{2}=\mathrm{T}_{\text {insp }}$ (for which the equation of motion can be solved according to Eq. 3) is superimposed by a ramp with negative slope starting at $\mathrm{t}_{1}=\mathrm{T}_{\text {ramp }}$ (Fig. 3). The solution during this phase of inspiration $\left(\mathrm{T}_{\text {Ramp }} \leq \mathrm{t} \leq \mathrm{T}_{\text {insp }}\right)$ can thus be derived as as follows:

$\mathrm{V}(\mathrm{t})=\mathrm{y}_{\text {ramp }}(\mathrm{t})-\mathrm{y}_{\text {ramp }}\left(\mathrm{t}-\mathrm{T}_{\text {Ramp }}\right)=\mathrm{P}_{\text {insp }} \cdot \mathrm{C}_{\mathrm{rs}} \cdot \mathrm{e}^{-\frac{\mathrm{t}}{\tau}}\left(\tau-\tau \cdot \mathrm{e}^{-\frac{\mathrm{T}_{\mathrm{ramp}}}{\tau}}\right)$

For our method, a change in $\mathrm{V}_{\mathrm{T}}$ was induced by performing a manual variation in pressure support level. When subtracting the breath after the change in $\mathrm{P}_{\text {insp }}$ from the preceding breath, we obtain:

$C_{\mathrm{rs}, \mathrm{PSV}}=\frac{\Delta \mathrm{V}_{T}}{\Delta P_{\mathrm{insp}}} \cdot \frac{T_{\text {ramp }}}{\tau \cdot e^{\frac{-T_{\text {insp }}}{\tau}} \cdot\left(1-e^{\frac{T_{\text {ramp }}}{\tau}}\right)}$ 


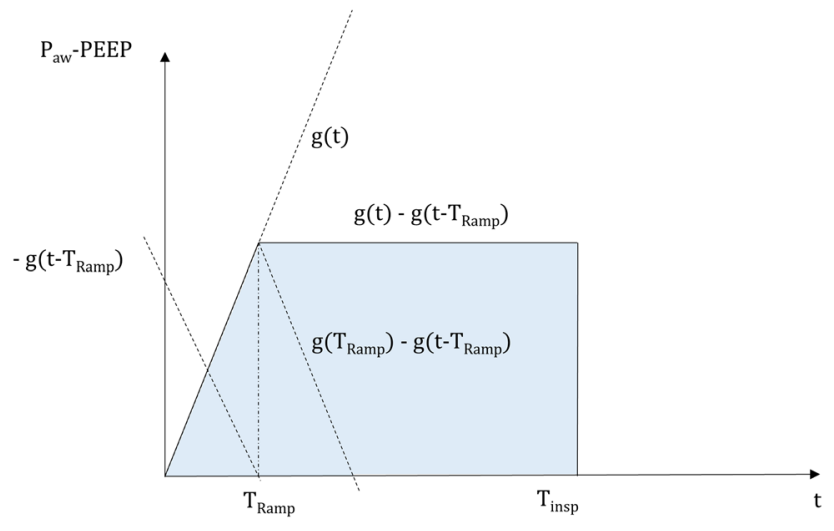

Fig. 3 Illustration of the linear superposition for determining the temporal behavior of the inspiratory volume. The superposition of the initial ramp by a negative ramp starting at $T_{\text {ramp }}$ yields the desired constant pressure until $\mathrm{T}_{\text {insp }}$

To compensate for natural variations in $\mathrm{P}_{\text {mus }}$, the median $\mathrm{C}_{\mathrm{rs}, \mathrm{PSV}}$ was calculated from all variations of pressure support level.

\subsection{Determination of reference values during VCV}

The reference value $\mathrm{C}_{\mathrm{rs}, \mathrm{VCV}}$ was calculated from the mean of five volume-controlled inspirations as follows:

$C_{\mathrm{rs}, \mathrm{VCV}}=\frac{V_{T}}{P_{\mathrm{plat}}-\mathrm{PEEP}}$

\subsection{Post-hoc analyses}

In a post-hoc analysis, intratidal $\mathrm{C}_{\mathrm{rs}}$ of the last slice of inspired volume $\left(\mathrm{C}_{\mathrm{rs}, \mathrm{VCVfin}}\right)$ was calculated using the SLICE method [4]. For this purpose, the inspiration during VCV was divided into six slices of equal volume, omitting the first and the last $5 \%$ of inspired volume. Assuming a constant $\mathrm{R}_{\mathrm{rs}}$ during the constant-flow phase of inspiration, $\mathrm{C}_{\mathrm{rs}, \mathrm{VCV} \text { fin }}$ was calculated from the last slice before the end of inspiration using a linear least-squares approximation.

Furthermore, we separately assessed the agreement between $\mathrm{C}_{\mathrm{rs}, \mathrm{PSV}}$ and $\mathrm{C}_{\mathrm{rs}, \mathrm{VCV}}$ as well as $\mathrm{C}_{\mathrm{rs}, \mathrm{VCV} f i n}$, respectively, for the subgroups of patients who did or did not require neuromuscular blockade during VCV. We also separately assessed the agreement between the values of $\mathrm{C}_{\mathrm{rs}, \mathrm{PSV}}$ that had been obtained from increases and decreases in PS $\left(\mathrm{C}_{\mathrm{rs}, \mathrm{PSV}+2}, \mathrm{C}_{\mathrm{rs}, \mathrm{PSV}-2}\right.$, respectively) and the reference value $\mathrm{C}_{\mathrm{rs}, \mathrm{VCV}}$.

Finally, we determined $\mathrm{C}_{\mathrm{rs}}$ with the method published by Al-Rawas and Co-Workers $\left(\mathrm{C}_{\mathrm{rs}, \tau \mathrm{e}}\right)$ in [12] according to the equation

$\mathrm{C}_{\mathrm{rs}, \tau e}=\frac{\mathrm{V}_{\mathrm{t}}+\tau_{\mathrm{e}}{ }^{* \text { inhaled flow rate }}}{\mathrm{P}_{\mathrm{aw}}-\text { PEEP }}$ where $\tau_{\mathrm{e}}$ was determined from the slope of the expiratory flow-volume curve between 0.1 and $0.5 \mathrm{~s}$ after the start of exhalation. Inhaled flow rate, $\mathrm{V}_{\mathrm{t}}$ and $\mathrm{P}_{\mathrm{aw}}$ were determined according to $[13,14]$ at a time point close to the end of inhalation, $50 \mathrm{~ms}$ before the beginning of exhalation.

\subsection{Blood gas analysis}

Arterial partial pressure of oxygen $\left(\mathrm{PaO}_{2}\right)$ with the corresponding inspired fraction of oxygen $\left(\mathrm{FiO}_{2}\right)$ were obtained from the last blood gas sample taken before the beginning of the study procedure.

\subsection{Statistical analyses}

The basic calculations were performed with Excel Version 2011 for Mac (Microsoft, Redmond, USA). For the statistical analyses, Prism Version 6 (GraphPad, La Jolla, USA) was used. The measured data were tested for normal distribution using the D'Agostino Pearson omnibus normality test. Data were compared to the reference measurement by a two-sided paired t test (if normally distributed) or by a Wilcoxon matched-pairs signed rank test (if not normally distributed). Correlation between values was assessed by linear regression. Bias and 95\% limits of agreement (LoA) were calculated by Bland-Altman analysis. All values are presented as means \pm standard deviations unless otherwise specified. Numerical values are presented as mean \pm standard deviation for normally distributed data or as median, 25 th-75th percentile for non-normally distributed data.

\section{Results}

The study protocol was successfully applied to all patients included in the study. Baseline characteristics of the studied patients are given in Table 1 . All values were normally distributed with the exception of P0.1. During VCV, the patients were ventilated with an average $\mathrm{V}_{\mathrm{T}}$ of $7.5 \pm 1.6 \mathrm{ml} /$ $\mathrm{kg}$ predicted body weight and a respiratory rate of $17.2 \pm 6.5$ breaths/min, resulting in a total minute ventilation of $7.9 \pm 1.5 \mathrm{~L} / \mathrm{min}$. During PSV, patients were ventilated with a $\mathrm{V}_{\mathrm{T}}$ of $8.9 \pm 2.1 \mathrm{ml} / \mathrm{kg}$ predicted body weight at a respiratory rate of $17.7 \pm 5.8$ breaths $/ \mathrm{min}$, resulting in a total minute ventilation of $9.7 \pm 2.4 \mathrm{~L} / \mathrm{min}$. The applied PEEP level was $10.3 \pm 3.2 \mathrm{cmH}_{2} \mathrm{O}$. The set PEEP level remained unchanged throughout the study period. The average $\mathrm{PaO}_{2} / \mathrm{FiO}_{2}$ ratio was $224 \pm 91 \mathrm{mmHg}$. The median P0.1 during PSV was 3.1, 1.9-4.1 $\mathrm{cmH}_{2} \mathrm{O} / 100 \mathrm{~ms}$. Neuromuscular blockade was required in 9 out of 20 patients. 
Table 1 Baseline characteristics of the studied patients

\begin{tabular}{|c|c|c|c|c|c|c|}
\hline ID & Diagnosis & Age (years) & Gender (m/f) & Height $(\mathrm{cm})$ & Weight (kg) & $\begin{array}{l}\text { Artificial } \\
\text { airway: }(\mathrm{Tu} / \mathrm{Tr} \\
\text { size) }\end{array}$ \\
\hline 1 & Trauma, ARDS (mild) & 41 & $\mathrm{~m}$ & 180 & 80 & Tu 8.0 \\
\hline 2 & Sepsis & 69 & $\mathrm{f}$ & 168 & 70 & Tu 7.5 \\
\hline 3 & Sepsis, ARDS (mild) & 40 & $\mathrm{~m}$ & 175 & 55 & $\operatorname{Tr} 9.0$ \\
\hline 4 & Sepsis, COPD & 72 & $\mathrm{~m}$ & 178 & 120 & $\operatorname{Tr} 9.0$ \\
\hline 5 & Sepsis & 55 & $\mathrm{f}$ & 163 & 122 & $\operatorname{Tr} 9.0$ \\
\hline 6 & Sepsis, ARDS (moderate) & 28 & $\mathrm{f}$ & 158 & 38 & Tu 7.0 \\
\hline 7 & Trauma, ARDS (moderate) & 60 & $\mathrm{~m}$ & 185 & 90 & Tu 8.0 \\
\hline 8 & Sepsis, ARDS (moderate) & 81 & $\mathrm{~m}$ & 170 & 110 & Tu 8.5 \\
\hline 9 & Trauma, ARDS (moderate) & 72 & $\mathrm{~m}$ & 170 & 90 & Tu 8.0 \\
\hline 10 & Sepsis, ARDS (moderate) & 57 & $\mathrm{~m}$ & 166 & 75 & Tu 8.0 \\
\hline 11 & Sepsis, ARDS (mild) & 38 & $\mathrm{f}$ & 160 & 82 & Tu 7.5 \\
\hline 12 & Postoperative & 77 & $\mathrm{~m}$ & 164 & 72 & Tu 8.5 \\
\hline 13 & Sepsis & 62 & $\mathrm{f}$ & 171 & 56 & Tu 7.5 \\
\hline 14 & Sepsis, ARDS (mild) & 71 & $\mathrm{~m}$ & 179 & 108 & $\operatorname{Tr} 9.0$ \\
\hline 15 & Postoperative & 60 & $\mathrm{~m}$ & 176 & 143 & Tu 8.0 \\
\hline 16 & Neurologic disorder & 50 & $\mathrm{f}$ & 166 & 60 & Tu 7.5 \\
\hline 17 & Pneumonia & 56 & $\mathrm{~m}$ & 163 & 60 & $\operatorname{Tr} 9,0$ \\
\hline 18 & Postoperative & 81 & $\mathrm{~m}$ & 178 & 80 & Tu 8.5 \\
\hline 19 & ARDS (moderate) & 70 & $\mathrm{~m}$ & 182 & 79 & $\operatorname{Tr} 9.0$ \\
\hline 20 & ARDS (mild) & 84 & $\mathrm{~m}$ & 170 & 89 & Tu 8.5 \\
\hline
\end{tabular}

Tu and $\mathrm{Tr}$ sizes refer to the inner diameter

ID patient identifier, $A R D S$ acute respiratory distress syndrome, $C O P D$ chronic obstructive pulmonary disease, $T u$ endotracheal tube, $\operatorname{Tr}$ tracheal cannula, $m$ male, $f$ female

\subsection{Determination of time constant during PSV}

Overall, $32 \%$ of all analyzed slices of the expiratory flowvolume curves during PSV had an $\mathrm{r}^{2}$ of higher than 0.95 . After excluding all remaining sections with $\mathrm{r}^{2}$ smaller than 0.95 , we found an average value of $0.69 \pm 0.20 \mathrm{~s}$ for $\tau_{\mathrm{PSV}}$. A detailed summary of the percentage of excluded slices for all sections analyzed can be found in Table 2 .

\subsection{Comparison of $\mathrm{C}_{\mathrm{rs}, \mathrm{PSV}}$ to $\mathrm{C}_{\mathrm{rs}, \mathrm{VCV}}$}

The average value of $\mathrm{C}_{\mathrm{rs}}, \mathrm{PSV}$ was $32 \pm 15 \mathrm{ml} / \mathrm{cmH}_{2} \mathrm{O}$ and differed significantly from the reference value $\mathrm{C}_{\mathrm{rs}}, \mathrm{VCV}$ $\left(39 \pm 16 \mathrm{ml} / \mathrm{cmH}_{2} \mathrm{O}, \mathrm{p}<0.0001\right)$. Both values were highly correlated $\left(\mathrm{r}^{2}=0.90 ; \mathrm{p}<0.0001\right)$. Bland-Altman analysis showed $95 \%$ limits of agreement ranging from -16.8 to $+2.7 \mathrm{ml} / \mathrm{cmH}_{2} \mathrm{O}$ (bias $-7 \mathrm{ml} / \mathrm{cmH}_{2} \mathrm{O}$ ) (Fig. 4).

\subsection{Comparison of $\mathrm{C}_{\mathrm{rs}, \mathrm{PSV}}$ to $\mathrm{C}_{\mathrm{rs}, \mathrm{VCV} \text { fin }}$}

Analyzing the compliance of the last slice of inspiratory volume using the SLICE-method, we found an average value of $\mathrm{C}_{\mathrm{rs}, \mathrm{VCV} f i n}$ of $34 \pm 14 \mathrm{ml} / \mathrm{cmH}_{2} \mathrm{O}$. This did not differ significantly from $\mathrm{C}_{\mathrm{rs}, \mathrm{PSV}}\left(32 \pm 15 \mathrm{ml} / \mathrm{cmH}_{2} \mathrm{O} ; \mathrm{p}=0.06\right)$. Linear regression revealed a good correlation between $\mathrm{C}_{\mathrm{rs}, \mathrm{PSV}}$ and $\mathrm{C}_{\mathrm{rs}, \mathrm{VCVfin}}\left(\mathrm{r}^{2}=0.87\right)$ and Bland-Altman methods comparison showed a small and statistically insignificant bias of $-2.4 \mathrm{ml} / \mathrm{cmH}_{2} \mathrm{O}$ and $95 \%$ limits of agreement ranging from -12.8 to $+7.9 \mathrm{ml} / \mathrm{cmH}_{2} \mathrm{O}$ (Fig. 5).
Table 2 Percentage of slices of expiratory flow-volume curves with $\mathrm{r}^{2}<0.95$

\begin{tabular}{llllllllll}
\hline Parameter & $\tau_{90-80}$ & $\tau_{80-70}$ & $\tau_{70-60}$ & $\tau_{60-50}$ & $\tau_{50-40}$ & $\tau_{40-30}$ & $\tau_{30-20}$ & $\tau_{20-10}$ & All \\
\hline Slices excluded & $84 \%$ & $78 \%$ & $72 \%$ & $62 \%$ & $57 \%$ & $59 \%$ & $62 \%$ & $68 \%$ & $68 \%$ \\
Standard deviation & 28 & 26 & 27 & 30 & 30 & 33 & 32 & 33 & 31 \\
\hline
\end{tabular}

$\tau_{90-80}, \tau_{80-70}$ etc. expiratory time constant, determined in the section between 90 and $80 \%\left(\tau_{90-80}\right), 80$ and $70 \%\left(\tau_{80-70}\right)$, etc. of expiratory tidal volume. See Fig. 2 for schematic description of the division of the expiratory flow-volume curve into slices of equal volume 


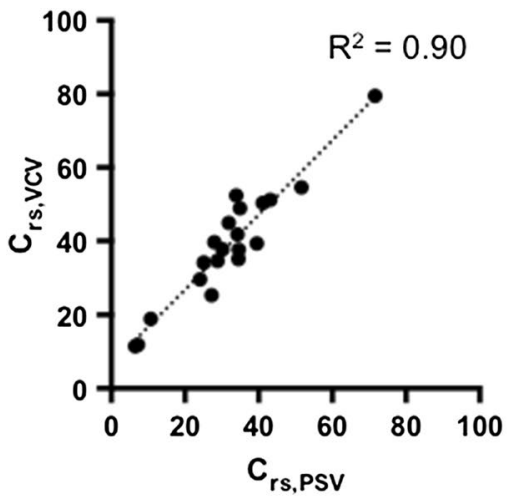

Fig. 4 Scatter plot and Bland-Altman plot of the calculated values for respiratory system compliance $\left(\mathrm{C}_{\mathrm{rs}}\right)$ measured during volume-controlled ventilation $\left(\mathrm{C}_{\mathrm{rs}, \mathrm{VCV}}\right)$ and during pressure support ventilation (PSV) with the new proposed method $\left(\mathrm{C}_{\mathrm{rs} \text {,PSV }}\right)$. In the scatter plot, the

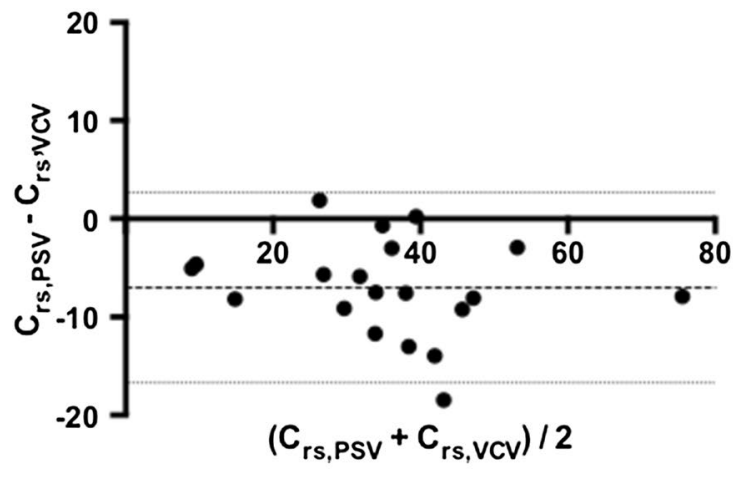

dotted line represents the best fit between the shown values. In the Bland-Altman plot, the dashed line represents the bias whereas the dotted lines represent the $95 \%$ limits of agreement. $R^{2}$ coefficient of determination

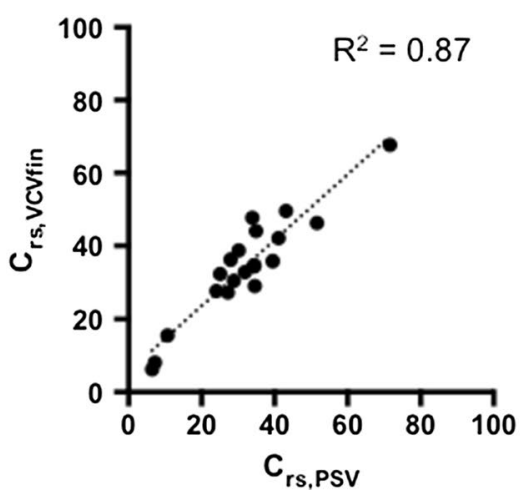

Fig. 5 Scatter plot and Bland-Altman plot of the calculated values for respiratory system compliance $\left(\mathrm{C}_{\mathrm{rS}}\right)$ measured during the last slice of volume-controlled inspiration $\left(\mathrm{C}_{\mathrm{rs}, \mathrm{VCV} \text { fin }}\right)$ and during pressure support ventilation (PSV) with the new proposed method $\left(\mathrm{C}_{\mathrm{rs}, \mathrm{PSV}}\right)$. In the

\subsection{Effect of neuromuscular blockade}

For the subgroup of 9 patients that required neuromuscular blockade to suppress spontaneous breathing activity during VCV, we found an average value of $\mathrm{C}_{\mathrm{rs}, \mathrm{PSV}}$ of $30 \pm 21 \mathrm{ml} / \mathrm{cmH}_{2} \mathrm{O}$ and an average value of $\mathrm{C}_{\mathrm{rs}, \mathrm{VCV}}$ of $38 \pm 22 \mathrm{ml} / \mathrm{cmH}_{2} \mathrm{O}$. This difference was statistically significant $(\mathrm{p}<0.0001)$. The correlation of $\mathrm{C}_{\mathrm{rs}, \mathrm{PSV}}$ and $\mathrm{C}_{\mathrm{rs}, \mathrm{VCV}}$ was excellent for this subgroup $\left(r^{2}=0.98 ; p<0.0001\right)$.

In the subgroup of 11 patients that did not require neuromuscular blockade to suppress spontaneous breathing activity during $\mathrm{VCV}$, we found an average value of $\mathrm{C}_{\mathrm{rs}, \mathrm{PSV} \text { of }} 34 \pm 8.2 \mathrm{ml} / \mathrm{cmH}_{2} \mathrm{O}$ and an average value of $\mathrm{C}_{\mathrm{rs}, \mathrm{VCV}}$ of $39 \pm 9.4 \mathrm{ml} / \mathrm{cmH}_{2} \mathrm{O}$. This difference was also statistically significant $(\mathrm{p}=0.008)$. The correlation of $\mathrm{C}_{\mathrm{rs}, \mathrm{PSV}}$ and $\mathrm{C}_{\mathrm{rs}, \mathrm{VCV}}$ was acceptable for this subgroup $\left(\mathrm{r}^{2}=0.61, \mathrm{p}=0.005\right)$. Figure 6 summarizes the subgroup scatter plot, the dotted line represents the best fit between the shown values. In the Bland-Altman plot, the dashed line represents the bias whereas the dotted lines represent the $95 \%$ limits of agreement. $R^{2}$ coefficient of determination

analyses for patients with and without the need for neuromuscular blockade during VCV.

\subsection{Separate comparison of $\mathrm{C}_{\mathrm{rs}, \mathrm{PSV}}$ from increases and decreases to $\mathrm{C}_{\mathrm{rs}, \mathrm{VCV}}$}

For $\mathrm{C}_{\mathrm{rs}, \mathrm{PSV}+2}$, which was calculated only from stepwise increases in pressure support, we found an average value of $30.3 \pm 20.3 \mathrm{ml} / \mathrm{cmH}_{2} \mathrm{O}$, which was positively correlated to $\mathrm{C}_{\mathrm{rs}, \mathrm{VCV}}\left(\mathrm{r}^{2}=0.80 ; \mathrm{p}<0.0001 ;\right.$ bias $=-8.7 \mathrm{ml} / \mathrm{cmH}_{2} \mathrm{O}, 95 \%$ limits of agreement -27.2 to $+9.9 \mathrm{ml} / \mathrm{cmH}_{2} \mathrm{O}$ ) (Fig. 7).

For $\mathrm{C}_{\mathrm{rs}, \mathrm{PSV}-2}$, which was calculated only from stepwise decreases in pressure support, we found an average value of $33.4 \pm 17.0 \mathrm{ml} / \mathrm{cmH}_{2} \mathrm{O}$, also with a positive correlation to $\mathrm{C}_{\mathrm{rs}, \mathrm{VCV}}\left(\mathrm{r}^{2}=0.72 ; \mathrm{p}<0.0001 ;\right.$ bias $=-5.5 \mathrm{ml} / \mathrm{cmH}_{2} \mathrm{O}, 95 \%$ limits of agreement -23.3 to $+12.2 \mathrm{ml} / \mathrm{cmH}_{2} \mathrm{O}$ ) (Fig. 7). 
Fig. 6 Scatter plots and BlandAltman plots of the calculated values for respiratory system compliance $\left(\mathrm{C}_{\mathrm{rs}}\right)$ measured during volume-controlled ventilation $\left(\mathrm{C}_{\mathrm{rs}, \mathrm{VCV}}\right)$ and during pressure support ventilation (PSV) with the new proposed method $\left(\mathrm{C}_{\mathrm{rs}, \mathrm{PSV}}\right)$, separated into the subgroups of patients who required neuromuscular blockade to suppress spontaneous breathing activity during VCV (above) and who did not require neuromuscular blockade during VCV (below). In the scatter plots, the dotted lines represent the best fit between the shown values. In the Bland-Altman plots, the dashed lines represent the bias whereas the dotted lines represent the $95 \%$ limits of agreement. $R^{2}$ coefficient of determination
Fig. 7 Scatter plots and BlandAltman plots of the calculated values for respiratory system compliance $\left(\mathrm{C}_{\mathrm{rs}}\right)$ measured during volume-controlled ventilation $\left(\mathrm{C}_{\mathrm{rs}, \mathrm{VCV}}\right)$ and with the new proposed method during pressure support ventilation just from increases in pressure support level $\left(\mathrm{C}_{\mathrm{rs}, \mathrm{PSV}+2}\right.$, above $)$ and just from decreases in pressure support level $\left(\mathrm{C}_{\mathrm{rs}, \mathrm{PSV}-2}\right.$, below) In the scatter plots, the dotted lines represent the best fit between the shown values. In the Bland-Altman plots, the dashed lines represent the bias whereas the dotted lines represent the $95 \%$ limits of agreement. $R^{2}$ coefficient of determination
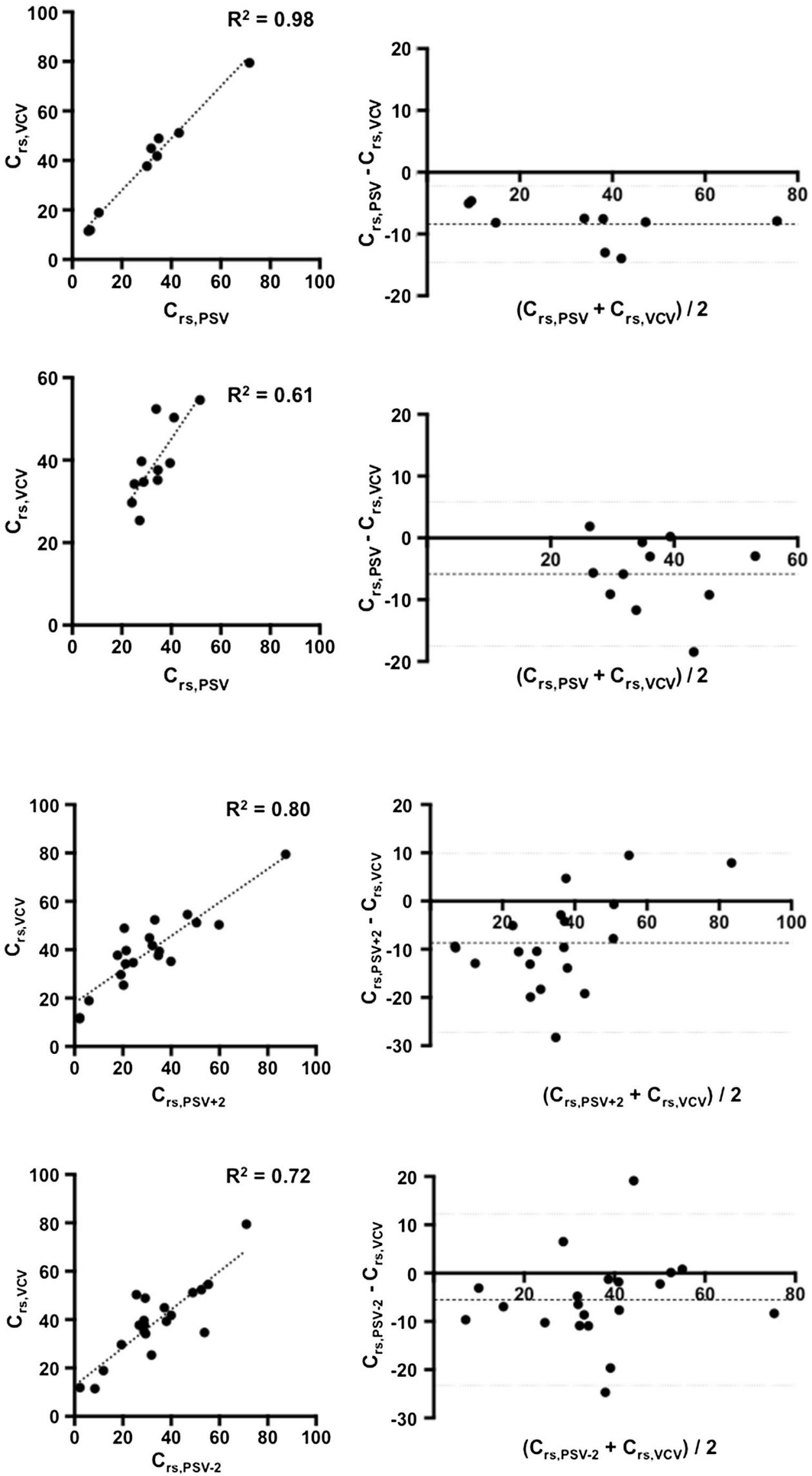
There was no statistically significant difference between $\mathrm{C}_{\mathrm{rs}, \mathrm{PSV}+2}$ and $\mathrm{C}_{\mathrm{rs}, \mathrm{PSV}-2}$.

\subsection{Comparison of $\mathrm{C}_{\mathrm{rs}, \tau \mathrm{e}}$ to $\mathrm{C}_{\mathrm{rs}, \mathrm{VCV}}$}

Applying the method proposed by Al-Rawas et al. we found an average value of $\mathrm{C}_{\mathrm{rs}, \tau \mathrm{e}}$ of $53 \pm 23 \mathrm{ml} / \mathrm{cmH}_{2} \mathrm{O}$. This was significantly higher than the reference value $\mathrm{C}_{\mathrm{rs}, \mathrm{VCV}}$ $\left(38 \pm 22 \mathrm{ml} / \mathrm{cmH}_{2} \mathrm{O} ; \mathrm{p}<0.0001\right)$. Bland Altman methods comparison revealed a bias of $+14.5 \mathrm{ml} / \mathrm{cmH}_{2} \mathrm{O}$ and $95 \%$ limits of agreement of -9.6 to $+38.6 \mathrm{ml} / \mathrm{cmH}_{2} \mathrm{O}$. There was an excellent correlation between $\mathrm{C}_{\mathrm{rs}, \tau \mathrm{e}}$ and $\mathrm{C}_{\mathrm{rs}, \mathrm{VCV}}\left(\mathrm{r}^{2}=0.74\right.$; $\mathrm{p}<0.0001$ ) (Fig. 8).

\section{Discussion}

In this pilot study, the non-invasive assessment of $\mathrm{C}_{\mathrm{rs}}$ during PSV showed a good correlation with the reference values measured during VCV. However, we found a significant underestimation of $\mathrm{C}_{\mathrm{rs}}$ with the new method. Comparing $\mathrm{C}_{\mathrm{rs}, \mathrm{PSV}}$ to the end-inspiratory value $\mathrm{C}_{\mathrm{rs}, \mathrm{VCV} 20}$, we still found a good correlation but no statistically significant bias. The $95 \%$ limits of agreement for $\mathrm{C}_{\mathrm{rs}}$ were relatively broad which could limit the new method's clinical applicability.

Assessment of $\mathrm{C}_{\mathrm{rs}}$ during any assisted mode of mechanical ventilation is challenging for several reasons. Not only is the patient's average $\mathrm{P}_{\text {mus }}$ generally unknown, but it can also exhibit a considerable breath-by-breath variability [17]. In our method, this breath-by-breath variability of $\mathrm{P}_{\text {mus }}$ was taken into account by performing repeated variations in pressure support level and by calculating the median $\mathrm{C}_{\mathrm{rs}, \mathrm{PSV}}$ from all variations that had been performed in an individual patient. Another challenge in the determination of $\mathrm{C}_{\mathrm{rs}}$ during PSV is the fact that there is no inspiratory plateau phase during PSV. Instead, there is generally a flow-dependent criterion for the termination of pressure support that can be adjusted according to the patient's individual needs and that, in our study, remained set to $25 \%$ of peak inspiratory flow, the default setting on our ventilators. Together with $\mathrm{T}_{\text {ramp }}$, which, depending on the patient's true $\mathrm{T}_{\text {insp }}$ accounts for a variable decrease in mean inspiratory $\mathrm{P}_{\mathrm{aw}}$, this pressure support termination criterion could lead to an underestimation of $\mathrm{C}_{\mathrm{rs}, \mathrm{PSV}}$ due to the absence of an end-inspiratory pause. In our study, we attempted to correct this underestimation by compensating for the actual $\mathrm{T}_{\text {ramp }}$ and $\mathrm{T}_{\mathrm{insp}}$, assuming a constant inspiratory and expiratory time constant (Eq. 5).

For this study, we decided to determine the time constant only from those slices of expiration that exhibited an almost linear flow-volume relationship. With this approach, we tried to avoid any phases of expiration with residual inspiratory muscle activity as well as phases of expiration with forced expiratory muscle activity. A linear flow-volume relationship is typical for passive emptying in a first-order model with one resistance and one compliance. However, a constant residual $\mathrm{P}_{\mathrm{mus}}$ during slices of exhalation would also result in a linear flow-volume relationship and cannot be detected by our method. Whether the proposed "slice" method is ideal for determining $\tau_{\mathrm{e}}$ during PSV and which is the ideal number of slices as well as the ideal cut-off value for $\mathrm{r}^{2}$ remains to be investigated.

Despite the good correlation between $\mathrm{C}_{\mathrm{rs}, \mathrm{PSV}}$ and $\mathrm{C}_{\mathrm{rs}, \mathrm{VCV}}$, the mean $\mathrm{C}_{\mathrm{rs}, \mathrm{PSV}}$ was significantly smaller than the mean $\mathrm{C}_{\mathrm{rs}, \mathrm{VCV}}$. This may be caused by several reasons. First, a small difference in $\mathrm{P}_{\text {mus }}$ caused by the variations in pressure support level cannot be entirely excluded. If the patient's $\mathrm{P}_{\mathrm{mus}}$ becomes smaller with higher pressure support level and vice versa, this would result in an underestimation of $\mathrm{C}_{\mathrm{rs}}$ with our method. Second, our model for correction of the pressure support termination criterion and $\mathrm{T}_{\text {ramp }}$ (Eq. 4)

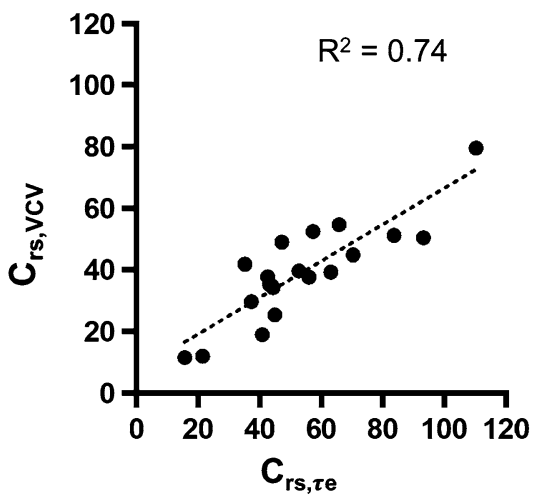

Fig. 8 Scatter plot and Bland-Altman plot of the calculated values for respiratory system compliance $\left(\mathrm{C}_{\mathrm{rs}}\right)$ measured during volume-controlled ventilation $\left(\mathrm{C}_{\mathrm{rs}, \mathrm{VCV}}\right)$ and during pressure support ventilation with the method proposed by Al-Rawas and coworkers $\left(\mathrm{C}_{\mathrm{rs}, \tau \mathrm{e}}\right)$. In the

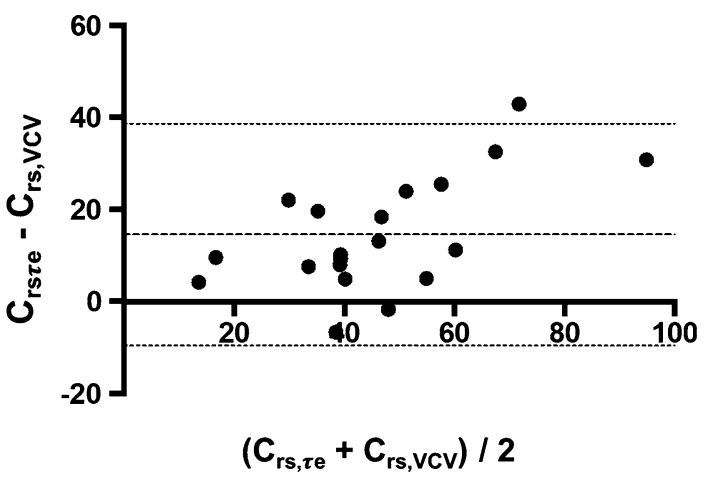

scatter plot, the dotted line represents the best fit between the shown values. In the Bland-Altman plot, the dashed line represents the bias whereas the dotted lines represent the $95 \%$ limits of agreement. $R^{2}$ coefficient of determination 
assumes the inspiratory pressure delivered by the ventilator to be constant after the end of the set ramp. This may not be the case during PSV, especially in patients with strong inspiratory effort (Fig. 1). Third, our approach is based on a simple one-compartment model of RSM that assumes $\mathrm{C}_{\mathrm{rs}}$ to be constant throughout the inspiratory period. In patients with heterogenous lung disease, $\mathrm{C}_{\mathrm{rs}}$ may show a volumedependent intratidal variability $[4,18]$. In cases of overdistension, where $\mathrm{C}_{\mathrm{rs}}$ becomes smaller during the "upper" part of the inspiratory pressure-volume loop, our method would underestimate the true value of $\mathrm{C}_{\mathrm{rs}}$. Therefore, the observed bias may have been caused by a certain degree of intratidal overdistension induced by the tidal volume of $8.9 \pm 2.1 \mathrm{ml} /$ $\mathrm{kg}$ predicted body weight during PSV at the clinically set PEEP of $10.3 \pm 3.2 \mathrm{cmH}_{2} \mathrm{O}$. This overdistension could have decreased respiratory system compliance in the course of inspiration. To test this hypothesis, we conducted a posthoc analysis, comparing $\mathrm{C}_{\mathrm{rs}, \mathrm{PSV}}$ to the end-inspiratory $\mathrm{C}_{\mathrm{rs}}$ during VCV, measured using the Slice method for the final part of inspired $\mathrm{V}_{\mathrm{T}}$. Remarkably, the bias between $\mathrm{C}_{\mathrm{rs}, \mathrm{PSV}}$ and $\mathrm{C}_{\mathrm{rs}, \mathrm{VCV} \text { fin }}$ was negligible and not statistically significant. Therefore, it seems likely that $\mathrm{C}_{\mathrm{rs}, \mathrm{PSV}}$ reflects $\mathrm{C}_{\mathrm{rs}}$ at the end of inspiration and is smaller than the average $\mathrm{C}_{\mathrm{rs}}$ in patients with overdistension. An assessment of $\mathrm{C}_{\mathrm{rs}, \mathrm{PSV}}$ at different levels of PEEP could further elucidate this relationship and is planned for future work. In combination with other methods for determination of $\mathrm{C}_{\mathrm{rs}}$ during PSV, our method might therefore be used as a diagnostic tool for determining overdistension.

\subsection{Alternative methods for determination of respiratory system mechanics during PSV}

Approximately 20 years ago, Iotti et al. demonstrated that it is possible to determine RSM during PSV [9]. In their study, the authors used high levels of pressure support aiming at decreasing $\mathrm{P}_{\text {mus }}$ to a minimum. This would then allow a proper calculation of the patients' respiratory system mechanics using a least-square fit method. However, applying high levels of pressure support may disturb the patients' breathing pattern and may influence the weaning course. Furthermore, this method is not able to provide continuous data of the breathing mechanics during weaning.

In 2001, Younes et al. introduced a method for the determination of $\mathrm{C}_{\mathrm{rs}}[11]$ and another method for the determination of $\mathrm{R}_{\mathrm{rs}}[19]$ during proportional assist ventilation (PAV). Both methods need a specially modified respirator which can automatically apply an end-inspiratory hold maneuver for determination of $\mathrm{C}_{\mathrm{rs}}$ and a short decrease of $\mathrm{P}_{\mathrm{aw}}$ ("pulse") during the early inspiratory phase for determination of $R_{r s}$. The authors found a good correlation for both methods when compared to reference values measured during controlled mechanical ventilation. These estimates of $\mathrm{C}_{\mathrm{rs}}$ and $\mathrm{R}_{\mathrm{rs}}$ can be used for automated control of PAV with load-adjustable gain factors [20] $(\mathrm{PAV}+)$. However, in a prospective observational study on post-cardiac surgery patients conducted by Patel and coworkers, evaluating the accuracy of $\mathrm{C}_{\mathrm{rs}}$ and $\mathrm{R}_{\mathrm{rs}}$ determined by the aforementioned method, unacceptably large bias of $-17 \mathrm{cmH}_{2} \mathrm{O}$ and $95 \% \mathrm{LoA}$ ranging -55 to $+22 \mathrm{cmH}_{2} \mathrm{O}$ were found for $\mathrm{C}_{\mathrm{rs}}$ when compared to the reference method [21]. Patel et al. concluded that the estimates of respiratory mechanics by PAV + are too inaccurate to be clinically useful. In view of these contradictory results of Younes et al. and Patel et al. regarding the accuracy of the measured RSM during PAV, it remains unclear whether this method provides valid values for $\mathrm{C}_{\mathrm{rs}}$ and $\mathrm{R}_{\mathrm{rs}}$ that can be used as a monitoring tool.

Recently, Al-Rawas and coworkers published a method for determination of plateau pressure, respiratory system compliance and total resistance during different ventilator modes using the expiratory time constant [12]. Similar to the method proposed in our manuscript, it is based on the assumption of similar inspiratory and expiratory time constants. However, since the equations proposed by Al-Rawas et al. do not incorporate a term for the $\mathrm{P}_{\text {mus }}$ generated by the patient, they require finding sections of the inspiratory cycle where $P_{\text {mus }}$ is equal to or close to zero $[13,14]$. When applying this method to the data from the present study, we found a significant bias of $+14.5 \mathrm{ml} / \mathrm{cmH}_{2} \mathrm{O}$, leading to an overestimation of $\mathrm{C}_{\mathrm{rs}}$ with this method. This could be explained by residual inspiratory muscle activity, despite the fact that we chose time points very close $(50 \mathrm{~ms})$ to the end of inspiration for this analysis.

Our method differs from the one proposed by AL-Rawas and coworkers in that it does not assume $\mathrm{P}_{\mathrm{mus}}$ to be zero. Instead, it applies a change in airway pressure for single breaths, assuming the induced change in $\mathrm{P}_{\mathrm{mus}}$ to be close to zero. The advantages of the method proposed by Al-Rawas are that it does not require any specific maneuver and can be used on a breath-by-breath basis. Furthermore, it allows calculation of resistance and plateau pressure, giving a full picture of a patient's respiratory mechanics regardless of ventilatory mode. Nevertheless, it could be inaccurate in patients with high respiratory drive, which is where our method may be advantageous for minimizing the confounding effect of the patient's inspiratory $\mathrm{P}_{\text {mus }}$.

\subsection{Limitations}

Our study has several limitations, which shall be addressed hereafter.

First, we cannot exclude a change in respiratory system mechanics caused by the switch from PSV to VCV and vice versa, which was accompanied by a deepening of sedation and, in some patients where this was not sufficient to suppress spontaneous breathing activity, neuromuscular 
paralysis. The loss of spontaneous breathing activity might have induced atelectases in some patients, leading to a smaller overall lung compliance. Confounding effects that could have been introduced by fluid shifts and viscous tissue effects in between the measurement periods can also not be entirely excluded.

Second and possibly related, the $95 \%$ limits of agreement between our method and the reference measurements for $\mathrm{C}_{\mathrm{rs}}$ were still relatively broad for clinical application. Nevertheless, they provide an estimate that is closer to the actual values than the LSF method ignoring the patient's $\mathrm{P}_{\text {mus }}$, which is currently employed by most ventilators and leads to gross overestimations in case of strong spontaneous efforts [9].

Third, our study was not designed to answer the important question whether the proposed method is able to accurately track changes in $\mathrm{C}_{\mathrm{rs}}$. This needs to be done in future work before applying this method in clinical practice.

Fourth, our method is based on the assumption of relatively similar respiratory time constants during inspiration and expiration. This may not be the case in patients with chronic obstructive lung diseases (COPD) or asthma. In fact, the only patient in our study who was diagnosed with (mild) COPD had an expiratory time constant of $0.47 \mathrm{~s}$, indicating there was no relevant expiratory air flow limitation in this patient. Therefore, we recommend that our method should presently not be applied in patients with expiratory air flow limitation caused by obstructive lung diseases.

Fifth, our method requires repeated changes in pressure support level and subsequent mathematical calculations that, when performed manually, are relatively time consuming. Due to the necessity of performing multiple repeated changes in PS level, obtaining a single value of $\mathrm{C}_{\mathrm{rs}}$ currently takes about 5-15 min, depending on the patient's respiratory rate, not taking into account any necessary computation time.

Nevertheless, the changes in pressure support level and the required calculations could easily be performed automatically by the ventilator in the future without disturbing the patient. This would allow a higher number of pressure support level changes to be performed and analyzed, which might enhance the accuracy of the calculated values for $\mathrm{C}_{\mathrm{rs}, \mathrm{PSV}}$, improving the method's clinical applicability. It may also improve the accuracy of our proposed method for determination of $\mathrm{C}_{\mathrm{rs}}$. An automatic application of the method is therefore highly desirable.

\section{Conclusions}

This pilot study shows that it is possible to determine values for $\mathrm{C}_{\mathrm{rs}}$ during PSV with the help of small changes of pressure support level. The derived values have a strong correlation but relatively broad limits of agreement when compared to reference values obtained during VCV and appear to provide an estimate of end-inspiratory $\mathrm{C}_{\mathrm{rs}}$. This simple measurement maneuver might improve the monitoring of patients undergoing assisted mechanical ventilation. For this purpose, it could be implemented as an automated maneuver in a respirator.

Acknowledgements The authors are indebted to Tom Leenhoven (CareFusion, Yorba Linda, USA) for his support. Furthermore, the authors thank all physicians and nurses from the two study intensive care units for their help and support during the whole study period. Above all, the authors are grateful to all patients and their relatives for their participation in this study.

\section{Compliance with ethical standards}

Conflict of interest TB, DS and NW received lecture fees and travel reimbursements from Dräger Medical Ag Co.KgaA. Lübeck, Germany. DS received consulting fees from Dräger Medical Ag Co.KgaA. Lübeck, Germany.

Ethical approval All procedures performed in studies involving human participants were in accordance with the ethical standards of the institutional and/or national research committee and with the 1964 Helsinki declaration and its later amendments or comparable ethical standards.

Informed consent Informed consent was obtained from all individual participants (or their legal representatives) included in the study.

\section{References}

1. Suter PM, Fairley B, Isenberg MD. Optimum end-expiratory airway pressure in patients with acute pulmonary failure. N Engl J Med. 1975;292:284-9. doi:10.1056/NEJM197502062920604.

2. Wiedemann HP, Matthay MA, Matthay RA. Cardiovascularpulmonary monitoring in the intensive care unit (Part 2). Chest. 1984;85:656-68.

3. Maisch S, Reissmann H, Fuellekrug B, Weismann D, Rutkowski T, Tusman G, Bohm SH. Compliance and dead space fraction indicate an optimal level of positive end-expiratory pressure after recruitment in anesthetized patients. Anesth Analg. 2008;106:175-81. doi:10.1213/01.ane.0000287684.74505.49.

4. Mols G, Brandes I, Kessler V, Lichtwarck-Aschoff M, Loop T, Geiger K, Guttmann J. Volume-dependent compliance in ARDS: proposal of a new diagnostic concept. Intensive Care Med. 1999;25:1084-91.

5. Grasso S, Terragni P, Mascia L, Fanelli V, Quintel M, Herrmann P, Hedenstierna G, Slutsky AS, Ranieri VM. Airway pressuretime curve profile (stress index) detects tidal recruitment/hyperinflation in experimental acute lung injury. Crit Care Med. 2004;32:1018-27. doi:10.1097/01.ccm.0000120059.94009.ad.

6. Grasso S, Stripoli T, De Michele M, Bruno F, Moschetta M, Angelelli G, Munno I, Ruggiero V, Anaclerio R, Cafarelli A, Driessen $\mathrm{B}$, Fiore T. ARDSnet ventilatory protocol and alveolar hyperinflation: role of positive end-expiratory pressure. Am J Respir Crit Care Med. 2007;176:761-7. doi:10.1164/rccm.200702-193OC.

7. Ferrando C, Suarez-Sipmann F, Gutierrez A, Tusman G, Carbonell J, Garcia M, Piqueras L, Compan D, Flores S, Soro M, Llombart A, Belda FJ. Adjusting tidal volume to stress index in an open lung condition optimizes ventilation and prevents 
overdistension in an experimental model of lung injury and reduced chest wall compliance. Crit Care. 2015;19:9. doi:10.1186/ s13054-014-0726-3.

8. Bellani G, Laffey JG, Pham T, Fan E, Brochard L, Esteban A, Gattinoni L, van Haren F, Larsson A, McAuley DF, Ranieri M, Rubenfeld G, Thompson BT, Wrigge H, Slutsky AS, Pesenti A, Investigators LS, Group ET. Epidemiology, patterns of care, and mortality for patients with acute respiratory distress syndrome in intensive care units in 50 countries. JAMA. 2016;315:788-800. doi:10.1001/jama.2016.0291.

9. Iotti GA, Braschi A, Brunner JX, Smits T, Olivei M, Palo A, Veronesi R. Respiratory mechanics by least squares fitting in mechanically ventilated patients: applications during paralysis and during pressure support ventilation. Intensive Care Med. 1995;21:406-13.

10. Foti G, Cereda M, Banfi G, Pelosi P, Fumagalli R, Pesenti A. End-inspiratory airway occlusion: a method to assess the pressure developed by inspiratory muscles in patients with acute lung injury undergoing pressure support. Am J Respir Crit Care Med. 1997;156:1210-6. doi:10.1164/ajrccm.156.4.96-02031.

11. Younes M, Webster K, Kun J, Roberts D, Masiowski B. A method for measuring passive elastance during proportional assist ventilation. Am J Respir Crit Care Med. 2001;164:50-60.

12. Al-Rawas N, Banner MJ, Euliano NR, Tams CG, Brown J, Martin $\mathrm{AD}$, Gabrielli A. Expiratory time constant for determinations of plateau pressure, respiratory system compliance, and total resistance. Crit Care. 2013; 17:R23. doi:10.1186/cc12500.

13. Al-Rawas N, Banner MJ, Euliano NR, Martin AD, Tarns C, Gabrielli A. Authors' response. Crit Care. 2013;17:421.

14. Becher T, Schadler D, Frerichs I, Weiler N. Non-invasive determination of respiratory system mechanics in pressure support ventilation using the expiratory time constant? Crit Care. 2013;17:424. doi: $10.1186 / \mathrm{cc} 12562$.
15. Viale JP, Duperret S, Mahul P, Delafosse B, Delpuech C, Weismann D, Annat G. Time course evolution of ventilatory responses to inspiratory unloading in patients. Am J Respir Crit Care Med. 1998; 157:428-34.

16. Sessler CN, Gosnell MS, Grap MJ, Brophy GM, O'Neal PV, Keane KA, Tesoro EP, Elswick RK. The Richmond AgitationSedation Scale: validity and reliability in adult intensive care unit patients. Am J Respir Crit Care Med. 2002;166:1338-44. doi:10.1164/rccm.2107138.

17. Gama de Abreu M, Spieth PM, Pelosi P, Carvalho AR, Walter C, Schreiber-Ferstl A, Aikele P, Neykova B, Hubler M, Koch T. Noisy pressure support ventilation: a pilot study on a new assisted ventilation mode in experimental lung injury. Crit Care Med. 2008;36:818-27. doi:10.1097/01.CCM.0000299736.55039.3A.

18. Karason S, Sondergaard S, Lundin S, Stenqvist O. Continuous on-line measurements of respiratory system, lung and chest wall mechanics during mechanic ventilation. Intensive Care Med. 2001;27:1328-39.

19. Younes M, Kun J, Masiowski B, Webster K, Roberts D. A method for noninvasive determination of inspiratory resistance during proportional assist ventilation. Am J Respir Crit Care Med. 2001;163:829-39.

20. Kondili E, Prinianakis G, Alexopoulou C, Vakouti E, Klimathianaki M, Georgopoulos D. Respiratory load compensation during mechanical ventilation-proportional assist ventilation with loadadjustable gain factors versus pressure support. Intensive Care Med. 2006;32:692-9. doi:10.1007/s00134-006-0110-0.

21. Patel AR, Taylor S, Bersten AD. Comparison of automated and static pulse respiratory mechanics during supported ventilation. Crit Care Resusc. 2012;14:130-4. 